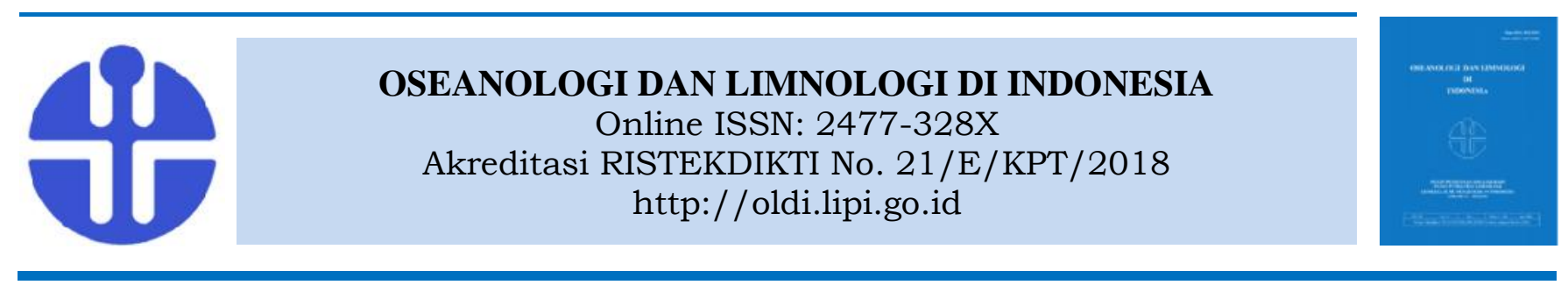

\title{
Pemanfaatan Teripang di Kabupaten Kaimana Provinsi Papua Barat
}

\author{
Nurul Dhewani Mirah Sjafrie ${ }^{1)}$ dan Ana Setyastuti ${ }^{1)}$ \\ ${ }^{1}$ Pusat Penelitian Oseanografi - Lembaga Ilmu Pengetahuan Indonesia, Jakarta. \\ Jl. Pasir Putih 1, Ancol Timur, Jakarta, Indonesia \\ E-mail: nuruldms@gmail.com
}

Submitted 2 March 2020. Reviewed 5 May 2020. Accepted 11 August 2020.

DOI: 10.14203/oldi.2020.v5i2.309

\begin{abstract}
Abstrak
Teripang merupakan salah satu komoditas laut yang diperdagangkan baik dalam skala lokal, nasional maupun internasional. Kabupaten Kaimana, Provinsi Papua Barat merupakan salah satu sentra penghasil teripang di Indonesia. Penangkapan teripang di kabupaten ini telah dilakukan sejak lama dengan memberlakukan sistem sasi. Tujuan penelitian ini adalah untuk mengetahui pemanfaatan teripang dengan sistem sasi. Pengambilan data dilakukan pada bulan April 2018 di dua lokasi, yaitu Pulau Kayumerah dan Kampung Kambala. Focus Group Discussion (FGD) dilakukan dengan bantuan pertanyaan terstruktur untuk mengumpulkan informasi tentang pemanfaatan teripang, sedangkan teknik snow balldigunakan untuk melacak para pengumpul teripang. Hasil penelitian menunjukkan bahwa di Pulau Kayumerah tercatat 22 spesies teripang yang bernilai ekonomis penting, sedangkan di Kampung Kambala tercatat 33 spesies. Jangka waktu buka-tutup sasi di Pulau Kayumerah adalah setiap dua sampai tiga tahun selama 14 hari, sedangkan di Kampung Kambala setiap dua tahun selama enam bulan. Rata-rata hasil tangkapan teripang di Pulau Kayumerah 3,57 kg kering/orang per hari dan di Kampung Kambala 0,09 kg kering/orang per hari, dan dijual ke kota. Sasi di lokasi penelitian tampaknya telah mengalami pergeseran dengan diterapkannya sistem lelang atau pengambilan teripang yang berbayar dan perubahan cara menangkap yaitu dengan menyelam menggunakan kompresor.
\end{abstract}

Kata Kunci: pemanfaatan, sasi, teripang, Kabupaten Kaimana.

\begin{abstract}
The Utilization of Sea Cucumber in Kaimana Regency, West Papua Province. Sea cucumbers are one of marine commodities that are traded at local, national and international scale. Kaimana Regency, West Papua Province is one of the sea cucumber producers in Indonesia. The exploitation of sea cucumber in this regency has been carried out for long times, applying thesasisystem. The purpose of this study is to determine the exploitation of sea cucumbers with the sasi system. Data were collected in April 2018 in two locations, namely Kayumerah Island and Kambala Village. Focus Group Discussion (FGD) was perfomed using structured questions to gather information of sea cucumber exploitation. The snowball technique was used to locate sea cucumber collectors. In this study 22 commercial species were found in Kayumerah Island and 33 species in Kambala Village. Duration of open-closed sasi in Kayumerah Island was 2 to 3 years for 14 days, while in Kambala Village was 2 years for 6 months. The average catched of sea cucumbers was $3.57 \mathrm{~kg}$ and $0.09 \mathrm{~kg}$ dry weight/person/ day in Kayumerah Island and Kambala Village respectively. These commodities were sold to the city nearby. Sasi system at the study site seems to have changed due to an
\end{abstract}


auction system or fee for collecting of sea cucumbers and a changes in capture methods, through diving supported by compressor.

Keywords: utilization, sasi, sea cucumbers, Kaimana Regency.

\section{Pendahuluan}

Teripang adalah kelompok timun laut yang termasuk ke dalam Kelas Holothuroidea, Filum Echinodermata. Teripang sudah sejak lama dikenal sebagai makanan lezat bagi masyarakat tertentu, terutama bagi masyarakat etnis Cina (Hartati et al., 2002). Selain sebagai komoditas makanan, teripang telah tervalidasi secara ilmiah dalam bidang pengobatan sebagai antitumor, antimikroba, antioksidan alami yang dibutuhkan dalam industri farmasi (Pangestuti et al., 2016; Pangestuti \& Arifin, 2018). Meningkatnya permintaan teripang untuk berbagai kepentingan menjadikan teripang sebagai komoditas yang semakin dicari, baik pada skala lokal maupun internasional. Kontribusi ekspor teripang dunia didominasi oleh Indonesia dan Filipina, yaitu sebesar 47\% (Choo, 2008). Indonesia merupakan negara peringkat kelima yang mengekspor teripang ke Hongkong (Konsul Perdagangan, 2016).

Saat ini, beberapa spesies teripang di Indonesia terindikasi telah mengalami tangkap lebih (over-exploited). Salah satu pemicunya adalah peningkatan harga eceran maksimum untuk produk grade-A sebesar lebih dari 50\% antara tahun 2011 dan 2016 atau 6,3\% per tahun. Kenaikan harga yang cepat mungkin merupakan efek gabungan dari meningkatnya permintaan produk kelas premium dan semakin terbatasnya pasokan produk dari negara-negara sumber teripang (Purcell et al., 2018). Wiadnyana et al., (2008) mengatakan bahwa populasi teripang di Indonesia cenderung mengalami penurunan, dilihat dari kepadatan yang relatif rendah, yaitu < 1 ind. $\mathrm{m}^{2}$.

Salah satu daerah penghasil teripang di Indonesia adalah Kabupaten Kaimana, Provinsi Papua Barat. Di kabupaten ini, sektor perikanan (termasuk teripang) memberikan kontribusi terbesar terhadap Produk Domestik Regional Bruto, yaitu sebesar 51,84\%, sedangkan kehutanan dan pertanian hanya menyumbang $31,26 \%$ dan 16,90\% (BPS, 2017). Pada tahun 2015 tercatat 6,1 ton teripang kering yang dikirim ke luar kabupaten (Dinas Perikanan Kaimana, 2017). Jumlah ini meningkat menjadi 8,2 ton pada tahun 2016 namun kemudian turun menjadi 5,2 ton pada tahun 2017.

122
Kontribusi besar sektor perikanan terhadap ekonomi Kabupaten Kaimana tersebut salah satunya ditunjang oleh kondisi perairan yang tergolong baik (KKP, 2015). KKP (2015) menyatakan bahwa persentase tutupan karang hidup di perairan Kaimana berkisar antara 22 $82 \%$ pada kedalaman 4-6 meter, 4 - 57\% pada kedalaman 12 - 15 meter dan $3-68 \%$ pada kedalaman $20-25$ meter. Hutan mangrove terdapat di Teluk Triton (Kaimana timur) masih tergolong asli dan cukup baik. Jumlah spesies ikan yang tercatat sebanyak 1.003 spesies, dengan spesies ikan yang umum dijumpai adalah Lutjanus decussatus, Parupeneus barberinus, Parupeneus multifasciatus, Ctenochaetus binotatus dan Scarus flavipectoralis.

Selain itu, sistem pengelolaan sumber daya laut di Kabupaten Kaimana juga berperan dalam menunjang perikanan di kabupaten ini. Sistem pengelolaan sumber daya alam tradisional yang diterapkan oleh masyarakat di kabupaten ini dikenal sebagai sasi Nggama, yang dapat dijumpai di Pulau Kayumerah, Kampung Namatota, Nasaulan, Kambala (Aditya, 2017) dan Adijaya, (Patriana et al., 2016; Aditya, 2017). Sasi adalah larangan untuk mengambil hasil sumberdaya alam tertentu sebagai upaya pelestarian demi menjaga mutu dan populasi sumberdaya hayatialam tersebut (Ummanah, 2013; Suntoko et al., 2016; Jugde \& Nuzrika 2008). Soulahy (2016) menambahkan bahwa sasiadalah larangan temporer dan suatu bentuk penertiban dalam mengelola sumber daya alam di darat maupun di laut; merupakan suatu lembaga adat untuk mengatur penggunaan dan pemilikan sumber daya alam dalam suatu daerah tertentu. Dengan demikian sasi memiliki peran secara sosial dan ekologis. Secara sosial, sasi berperan sebagai, pendidik dan pembentuk sikap serta perilaku masyarakat, juga merupakan upaya untuk memelihara tata krama hidup bermasyarakat, termasuk upaya pemerataan dan pembagian pendapatan dari sumber daya alam (Judge \& Nurizka, 2008; Kuwati et al., 2014a). Secara ekologis, sasi berperan sebagai sarana pengamanan terhadap pelestarian sumber daya alam dan lingkungan (Kuwati et al., 2014a), yang memberikan kesempatan kepada makhluk hidup (sumber daya hayati) untuk berkembang biak dan 
memperbanyak populasi (Judge \& Nurizka, 2008).

Penelitian dan kajian tentang sasi dari berbagai aspek dan lokasi telah banyak dipublikasikan, salah satunya tentang tata cara pelaksanaan sasi telah dipublikasilan oleh Soulhany (2016) di Negeri Rumahsoal, Kecamatan Taniwel, Kabupaten Seram Bagian Barat dan Warawarin et al. (2018) di Desa Ohoirenan dan Yamtel, Kabupaten Maluku tenggara. Kajian tentang efektifitas sasi dalam pelestarian sumber daya alam dilaporkan dari Desa Eti Kecamatan Seram Barat, Kabupaten Seram (Judge \& Nurizka, 2008); Kampung Foley, Distrik Misool Timur (Kuwati et al., 2014b); Desa Soloflof, Kabupaten Sorong (Suntoko et al., 2016) dan Negeri Haruku, Kecamatan Haruku, Kabupaten Maluku Tengah (Asrul et al., 2017). Selanjutnya, dinamika yang terjadi dalam sasi telah dipublikasikan oleh Mc Leod et al. (2009) di Tomotol dan Fafanlap, Kabupaten Raja Ampat; Karepesina et al. (2013) di Desa Haruku, Kabupaten Maluku Tengah; Elfemi (2015) di Desa Adaut, Kecamatan Selaru, Kabupaten Maluku Tenggara Barat; Lestari dan Satria (2015) di Distrik Misool Barat; Patriana et al. (2016) di Kampung Adijaya, Distrik Buruway, Kabupaten Kaimana; Ananingsih (2018) di Kepulauan Kei; Betaubun et al. (2019) di Desa Taar, Ngilngof, Selayar, Revav, dan Desa Tetoat Kepulauan Kei serta Putri et al. (2020) di Kampung Foley, Distrik Misool Timur, Kabupaten Raja Ampat. Kajian tentang sasi sebagai satu alat untuk mengatasi konflik pemanfaatan sumber daya laut di Desa Ohoider Tawun, Kecamatan Kei Kecil, Kabupaten Maluku Tenggara telah dilaporkan oleh Kusapy et al. (2005). Dari semua publikasi di atas, tampaknya belum ditemukan hasil penelitian sasi yang mengkaji secara mendalam tentang sumber daya teripang sebagai spesies, jumlah yang diperoleh, dan alur pemasaran pada saat sasi dibuka. Keadaan inilah yang mendorong penulis untuk mengetahui bagaimana pemanfaatan teripang di Kabupaten Kaimana berbasis sasi dari aspek tersebut.

\section{Metodologi}

\section{Lokasi dan Waktu Penelitian}

Penelitian dilakukan di Kabupaten Kaimana, Provinsi Papua Barat.Kabupaten ini terletak pada $132^{0} 75^{\prime}-135^{0} 15^{\prime}$ Bujur Timur dan $02^{\circ} 90^{\prime}-04^{0} 20^{\prime}$ Lintang Selatan (BPS, 2016c). dengan luas wilayah $36.000 \mathrm{~km}^{2}$ yang terdiri atas $18.500 \mathrm{~km}^{2}$ daratan dan $17.500 \mathrm{~km}^{2}$ lautan. Kaimana meliputi tujuh kecamatan (distrik) dan 84 kampung/desa serta dua kelurahan, dengan 64\% kampung terletak di daerah pesisir (BPS, 2016c). Penelitian ini dilaksanakan pada tanggal 4 - 10 April 2018 dan dilakukan di dua lokasi.yaitu Pulau Kayumerah (yang termasuk ke dalam Kampung Nariki) mewakili bagian timur, sedangkan Kampung Kambala mewakili bagian barat Kabupaten Kaimana (Gambar 1). 


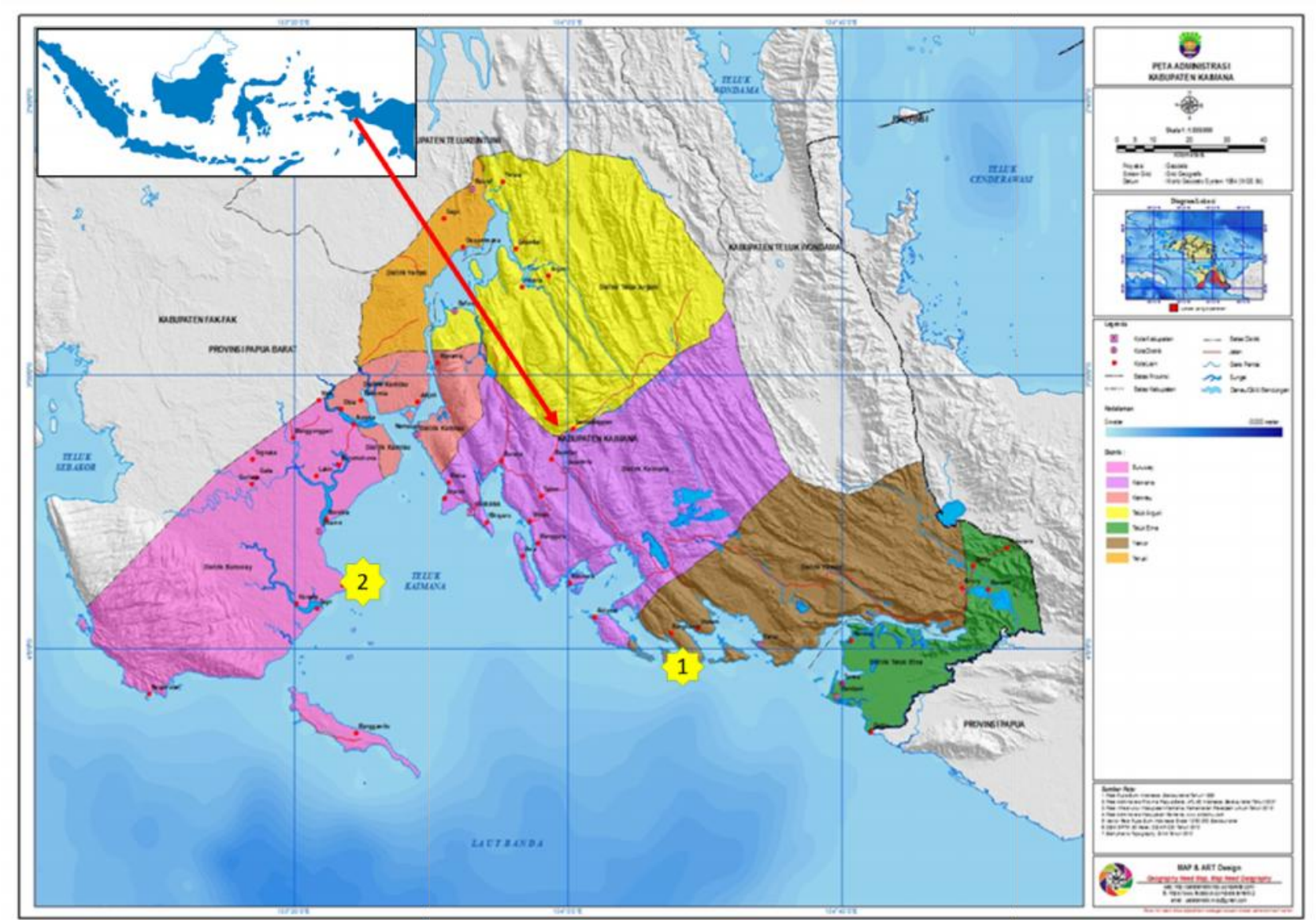

Sumber: https://petatematikindo.files.wordpress.com/2013/02/administrasi-kaimana.jpg

Gambar 1. Lokasi penelitian (1 = Pulau Kayumerah; 2 = Kampung Kambala).

Figure 1 . Study location $(1=$ Kayumerah Island; $2=$ Kambala Village $)$.

\section{a. Pulau Kayumerah}

Pulau Kayumerah termasuk ke dalam wilayah administrasi Kampung Nariki, Distrik Teluk Etna. Dari Kaimana, pulau ini dapat ditempuh melalui jalur laut selama 2,5 jam dengan menggunakan perahu motor 80 PK. Kampung Nariki dihuni oleh 336 jiwa yang terdiri atas 70 Kepala Keluarga (KK), yang tersebar pada wilayah seluas 7,4 $\mathrm{km}^{2}$ (BPS, 2016b). Suku yang ada di kampung ini mayoritas adalah suku Koiwai Boimasa. Nelayan yang tinggal di Pulau Kayumerah sebagian besar adalah nelayan tangkap dan nelayan budi daya (rumput laut).

Di sekitar Pulau Kayumerah terdapat beberapa pulau kecil. Lokasi sasi ditetapkan di sekeliling pulau-pulau kecil tersebut. Daerah ini relatif terlindung, dengan mangrove tumbuh di sekeliling pulau. Substrat perairan ditumbuhi oleh lamun dan makroalga. Berdasarkan pengamatan singkat diketahui, spesies lamun yang tumbuh didominasi oleh Thalassia hemprichii, sedangkan makroalgae yang tercatat adalah marga Padina dan Halimeda.

\section{b. Kampung Kambala}

Kampung Kambala termasuk ke dalam wilayah administrasi Distrik Buruway. Dari Kota Kaimana, kampung ini dapat ditempuh melalui jalur laut selama dua jam dengan menggunakan perahu motor 80 PK. Kampung ini dihuni oleh 636 jiwa, yang terdiri atas $137 \mathrm{KK}$, yang tersebar pada wilayah seluas $14,04 \mathrm{~km}^{2}$ (BPS, 2016a). Mata pencaharian penduduk sebagian besar sebagai nelayan, sisanya sebagai petani dan pedagang.

Lokasi yang ditetapkan sebagai lokasi sasi terletak di perairan yang berada di depan Kampung Kambala dan Pulau Karufa. Kedua lokasi ini memiliki morfologi pantai berbeda. Lokasi pertama, di depan Kampung Kambala, memiliki paparan terumbu (reef flat) relatif panjang dibandingkan dengan Pulau Karufa, dengan substrat ditumbuhi oleh lamun spesies Enhalus acoroides dan Thallasia hemrprichii. Pulau Karufa memiliki paparan terumbu pendek dan sempit, subsratnya merupakan hamparan karang mati yang ditutupi silt dan makroalga dari 
marga Sargassum tampak mendominasi. Lereng terumbu pulau ini relatif curam dan dijumpai karang boulder dan bercabang.

\section{Pengumpulan Data}

Data pemanfaatan dan pengelolaan teripang diperoleh dari data primer dan data sekunder. Data primer diambil melalui teknik Focus Group Discussion (FGD) dengan 'petuanan'(tetua adat), aparat kampung dan masyarakat setempat untuk memperoleh informasi tentang kegiatan penangkapan teripang. Peserta FGD di Pulau Kayumerah berjumlah 13 orang yang terdiri dari delapan orang laki-laki dan lima orang perempuan, sedangkan di Kampung Kambala delapan orang semuanya laki-laki. Selain itu dilakukan pula wawancara dengan pertanyaan terstruktur dan observasi lapangan. Informasi yang dikumpulkan adalah spesies teripang, alat tangkap, waktu penangkapan dan jumlah tangkapan. Untuk mengetahui spesies teripang, buku panduan yang berisi spesies teripang (Puslit Oseanografi, 2018) ditunjukkan kepada responden, selanjutnya responden menyebutkan nama lokal teripang yang diambil (Gambar 2.). Teknik snowball dilakukan untuk melacak pengumpul teripang. Data sekunder dikumpulkan dari instansi terkait, misalnya Dinas Perikanan Kabupaten Kaimana, Badan Pusat Statistik Kabupaten Kaimana serta publikasi lainnya.

\section{Analisis Data}

Data yang diperoleh dianalisis berdasarkan sumber daya teripang, pemanfaat (nelayan dan pengepul) serta pola pemanfaatan dengan sistem sasi. Data ditabulasi, dibuat diagram dan diuraikan secara deskriptif.

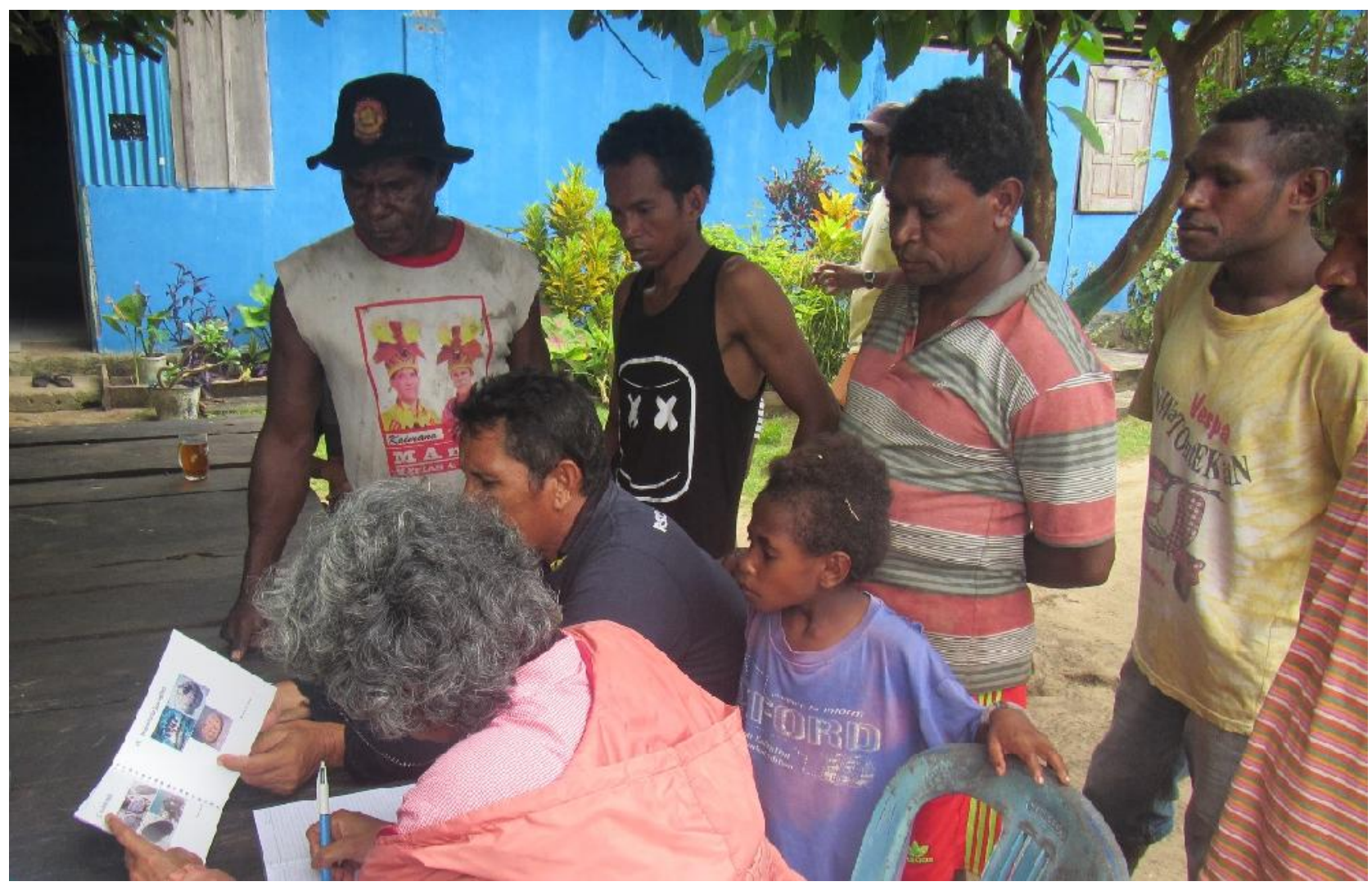

Gambar 2. Pengambilan data spesies teripang.

Figure 2. Data collection of sea cucumber species.

\section{Hasil}

\section{Sumber Daya Teripang}

Hasil FGD dan wawancara menunjukkan bahwa ada 22 spesies teripang yang biasa diambil oleh masyarakat di Pulau Kayumerah dan 33 spesies di Kampung Kambala. Menariknya, masing-masing kampung memberi nama yang berbeda untuk beberapa spesies teripang (Tabel 1). 
Sjafrie \& Setyastuti

Tabel 1. Spesies teripang yang diambil oleh nelayan di dua lokasi.

Table 1. List of sea cucumber species collected by fishers on two locations.

\begin{tabular}{|c|c|c|c|c|c|}
\hline \multirow{2}{*}{ No } & \multirow{2}{*}{ Scientific name } & \multicolumn{2}{|c|}{ Local Name } & \multicolumn{2}{|c|}{ Occurence } \\
\hline & & Kayumerah Island & Kambala Village & Kayumerah & Kambala \\
\hline 1 & Actinopyga lecanora & guci & guci & $\sqrt{ }$ & $\sqrt{ }$ \\
\hline 2 & Actinopyga caerulea & gosong laut & gosong laut & $\sqrt{ }$ & $\sqrt{ }$ \\
\hline 3 & Actinopyga miliaris & teripang raja, guci batu & teripang raja & $\sqrt{ }$ & $\sqrt{ }$ \\
\hline 4 & Actinopyga mauritiana & benang laut & terompet & $\sqrt{ }$ & $\sqrt{ }$ \\
\hline 5 & Actinopyga echinites & teripang raja, guci batu & batu-batu & & $\sqrt{ }$ \\
\hline 6 & Bohadschia argus & benang laut & benang batu & & $\sqrt{ }$ \\
\hline 7 & Bohadschia subrubra & & batu pasir & & $\sqrt{ }$ \\
\hline 8 & $\begin{array}{l}\text { Bohadschia } \\
\text { marmorata }\end{array}$ & benang darat & benang darat & $\sqrt{ }$ & $\sqrt{ }$ \\
\hline 9 & Bohadschia vitiensis & & benang pasir & $\sqrt{ }$ & $\sqrt{ }$ \\
\hline 10 & $\begin{array}{l}\text { Pearsonothuria } \\
\text { graeffei }\end{array}$ & terompet & terompet & $\sqrt{ }$ & $\sqrt{ }$ \\
\hline 11 & Holothuria atra & karet hitam & karet & $\sqrt{ }$ & $\sqrt{ }$ \\
\hline 12 & Holothuria coluber & teripang ular & teripang ular & $\sqrt{ }$ & $\sqrt{ }$ \\
\hline 13 & $\begin{array}{l}\text { Holothuria } \\
\text { leucospilota }\end{array}$ & sepatu & teripang ular & $\sqrt{ }$ & $\sqrt{ }$ \\
\hline 14 & $\begin{array}{l}\text { Holothuria } \\
\text { fuscopunctata }\end{array}$ & & sepatu & $\sqrt{ }$ & $\sqrt{ }$ \\
\hline 15 & Holothuria nobilis & teripang susu & teripang susu & $\sqrt{ }$ & $\sqrt{ }$ \\
\hline 16 & Holothuria fuscogilva & teripang susu & teripang susu & $\sqrt{ }$ & $\sqrt{ }$ \\
\hline 17 & Holothuria lesson & benang laut & gosok laut & & $\sqrt{ }$ \\
\hline 18 & Holothuria scabra & tidak ada & gosok darat & $\sqrt{ }$ & $\sqrt{ }$ \\
\hline 19 & Holothuria impatiens & terompet & terompet & & $\sqrt{ }$ \\
\hline 20 & $\begin{array}{l}\text { Holothuria } \\
\text { flavomaculata }\end{array}$ & teripang ular & teripang anjing & & $\sqrt{ }$ \\
\hline 21 & Holothuria edulis & karet/dada merah & dada merah & $\sqrt{ }$ & $\sqrt{ }$ \\
\hline 22 & $\begin{array}{l}\text { Holothuria } \\
\text { fuscocinerea }\end{array}$ & benang pasir & benang karang & & $\sqrt{ }$ \\
\hline 23 & Holothuria hilla & teripang ular & terompet & & $\sqrt{ }$ \\
\hline 24 & Holothuria pervicax & teripang air malam & teripang air malam & $\sqrt{ }$ & $\sqrt{ }$ \\
\hline 25 & Stichopus cloronotus & teripang jepang & teripang jepang & $\sqrt{ }$ & $\sqrt{ }$ \\
\hline 26 & Stichopus ocellatus & teripang air malam & teripang air siang & & $\sqrt{ }$ \\
\hline 27 & Stichopus vastus & teripang air malam & teripang air siang & & $\sqrt{ }$ \\
\hline 28 & Stichopus herrmanni & teripang air malam & teripang air siang & & $\sqrt{ }$ \\
\hline 29 & Stichopus horrens & teripang nanas & teripang air malam & $\sqrt{ }$ & $\sqrt{ }$ \\
\hline 30 & $\begin{array}{l}\text { Stichopus } \\
\text { pseudohorrens }\end{array}$ & teripang nanas & teripang air malam & $\sqrt{ }$ & $\sqrt{ }$ \\
\hline 31 & Thelenota anax & teripang duyung & teripang duyung & $\sqrt{ }$ & $\sqrt{ }$ \\
\hline 32 & Thelenota rubralienata & teripang duyung & teripang duyung & $\sqrt{ }$ & $\sqrt{ }$ \\
\hline \multirow[t]{2}{*}{33} & Thelenota ananas & teripang nanas & teripang nanas & $\sqrt{ }$ & $\sqrt{ }$ \\
\hline & & & $\begin{array}{l}\text { TOTAL NUMBER OF } \\
\text { SPECIES }\end{array}$ & 22 & 33 \\
\hline
\end{tabular}

Source: primary data (2018) 


\section{Nelayan Teripang}

Nelayan teripang di Pulau Kayumerah maupun Kampung Kambala sejatinya adalah nelayan penangkap ikan. Pada saat sasi dibuka barulah mereka mengalihkan target tangkapannya dari ikan menjadi teripang. Dari data yang diperoleh diketahui bahwa jumlah nelayan di Pulau Kayumerah adalah sekitar 70 KK, sedangkan di Kampung Kambala adalah 137 KK, tercatat 132 nelayan yang semuanya melakukan penangkapan teripang pada saat sasi dibuka.

Para nelayan menangkap teripang saat air surut jauh ('meti') di paparan terumbu (reef flat) sampai ke lereng (reef slope). Mereka yang mengambil teripang di area paparan terumbu, cukup dengan berjalan kaki, sedangkan yang menangkap di lereng terumbu menggunakan alat tangkap penikam. Untuk sampai ke lereng terumbu mereka menggunakan perahu dayung atau perahu kayu dengan motor tempel. Pada daerah lereng terumbu yang relatif dalam, nelayan menggunakan kompresor untuk menyelam. Waktu penangkapan teripang di kedua kampung umumnya dilakukan pada musim barat (September-April). Lokasi penangkapan adalah perairan sekitar Pulau Kayumerah, Pulau Aiduma dan Tanah Besar (nelayan Pulau Kayumerah) dan perairan di sekitar Kampung Kambala serta Pulau
Karufa (nelayan Kampung Kambala). Pada saat sasi, selain mereka berbondong-bondong menangkap teripang, pekerjaan menangkap ikan pun masih tetap dilakukan. Setelah sasi selesai sebagian besar nelayan melakukan pekerjaan sambilan sebagai petani. Selain nelayan kampung setempat, ada pula nelayan dari luar kampung, namun mereka tidak ikut dalam penangkapan teripang, hanya menangkap ikan.

Hasil tangkapan teripang di kedua lokasiberbeda. Di Pulau Kayumerah hasil tangkapan adalah $50 \mathrm{~kg}$ kering per orang per dua minggu atau 3,57 kg teripang kering per orang per hari, sedangkan di Kampung Kambala hasil tangkapan adalah 1 ton kering per enam bulan atau $0,09 \mathrm{~kg}$ teripang kering per orang per hari. Hasil wawancara menunjukkan bahwa terjadi penurunan hasil tangkap dibandingkan 10 tahun terakhir di Pulau Kayumerah, sedangkan di Kampung Kambala hasil tangkap tidak mengalami penurunan atau penambahan.Teripang hasil tangkapan dibeli oleh pengepul yang datang dari Kaimana setelah sasi selesai. Sebelum dijual ke pengepul, teripang diproses terlebih dahulu yaitu dengan cara dibersihkan isi perutnya, dimasak, diasar (diasap) dan dikeringkan. Untuk teripang susu tidak ada penanganan khusus, teripang hanya digarami.

Tabel 2. Praktik penangkapan teripang di Pulau Kayumerah dan Kampung Kambala.

Table 2. Sea cucumber fishing practice in Kayumerah Island and Kambala Village.

\begin{tabular}{|l|l|l|}
\hline Questions & \multicolumn{1}{|c|}{ Kayumerah Island } & \multicolumn{1}{c|}{ Kambala Village } \\
\hline Time of harvest & $\begin{array}{l}\text { Northwest monsoon season } \\
\text { (September-April), at a low tide }\end{array}$ & $\begin{array}{l}\text { Northwest monsoon season } \\
\text { (September-April), at a low tide }\end{array}$ \\
\hline Type of boat & Boat with small machine & Row boat \\
\hline How to catch & On foot, diving & On foot, diving \\
\hline Catch Location & Dramai isl, Aiduma isl, Tanah Besar & Kambala village, Karufa isl \\
\hline Post-harvest handling & Sold dry & $\begin{array}{l}\text { Sold dry; Holothuria nobilis are sold } \\
\text { wet after salting }\end{array}$ \\
\hline Amount of catches & 50 kg dry weight/person/2 week & 1 ton dry weight/6 months \\
\hline Sold at & Kaimana, taken by collectors & Kaimana, taken by collectors \\
\hline Price/kg & Depend on species & Depend on species \\
\hline The catch compared to 10 years ago & less & same \\
\hline Other work while waiting for Sasi & Fishing, farming & Fishing, farming \\
\hline $\begin{array}{l}\text { Are there outside fishermen who come } \\
\text { to take sea cucumbers? }\end{array}$ & No & No \\
\hline
\end{tabular}

\section{Pengepul Teripang}

Berdasarkan informasi nelayan dari kedua kampung, ditemukan lima orang pengepul teripang yang semuanya berlokasi di Kabupaten Kaimana (Tabel 3). Dari kelima pengepul tersebut, hanya satu pengepul yang fokus kepada penjualan teripang, sedangkan empat pengepul lainnya fokus pada penjualan ikan, sirip hiu, minyak hiu dan lobster, teripang hanya merupakan penjualan sampingan. 
Tabel 3. Pengepul teripang di Kabupaten Kaimana.

Table 3. Sea cucumber collectors in Kaimana Regency.

\begin{tabular}{|c|l|c|l|}
\hline No. & \multicolumn{1}{|c|}{ Collector location } & Start & \multicolumn{1}{|c|}{ Sea cucumber origin } \\
\hline 1 & Jembatan Air Tiba & 1997 & Kaimana, Adijaya \\
\hline 2 & Lapangan Cendrawasih & 2001 & Namatota, Lakahia, Totawae, Ombak, Panbi \\
\hline 3 & Seram Village & 2005 & Adijaya, Kayumerah, Namatota, Kambala \\
\hline 4 & Anda Air Village & 2017 & Adijaya, Nasa Ulan, Mai-mai, Kayumerah \\
\hline 5 & Kaimana Market & 2018 & Anda Air, Sisir \\
\hline
\end{tabular}

Source: Primary Data (2018)

Teripang dibeli oleh para pengepul dalam kondisi basah ataupun kering. Di tingkat pengepul, baik teripang kering maupun basah diolah lagi sebelum dikirim ke pengepul besar yang berada di Surabaya. Gambar 3 berikut memperlihatkan proses pengolahan teripang di tingkat pengepul. Pengolahan ini dilakukan agar harga teripang yang dijual ke pengepul besar tetap stabil, karena telah memenuhi kriteria, yaitu dari aspek kekeringan, tingkat kematangan serta penampilanteripang. Apabila ketiga kriteria tersebut tidak terpenuhi, maka harga teripang menjadi rendah.

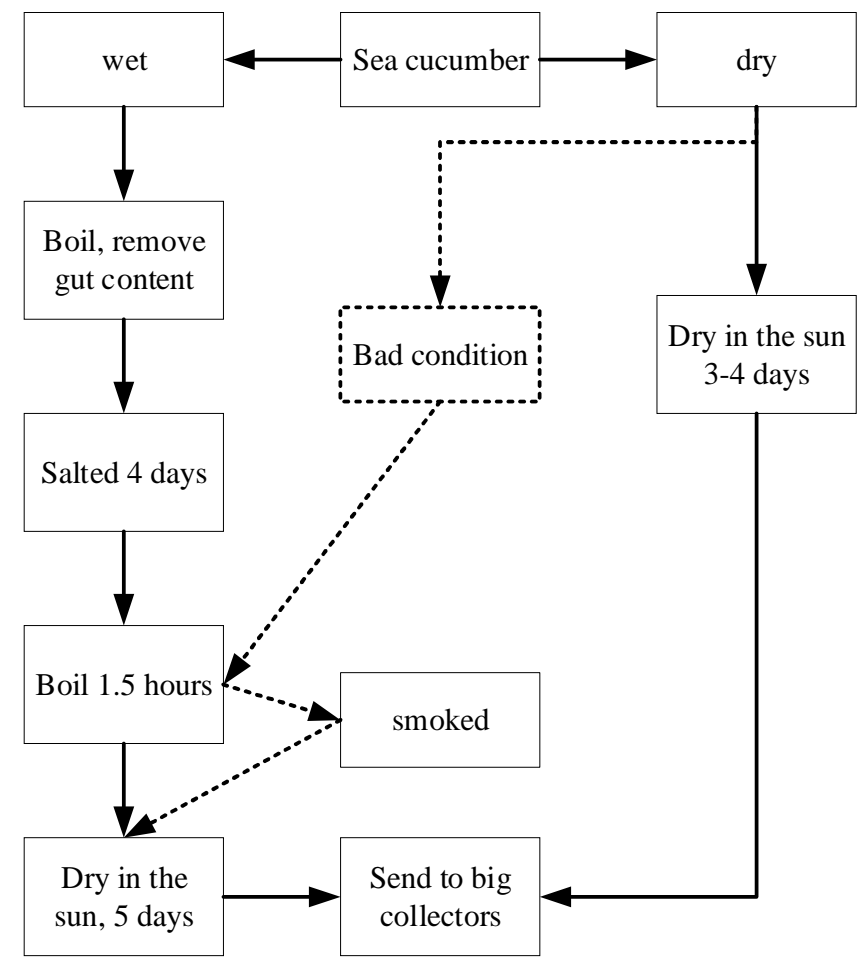

Gambar 3. Proses pengolahan teripang di tingkat pengepul (sumber: data primer 2018).

Figure 3. Sea cucumber processing at the collector level (source: primary data 2018).

\section{Penangkapan Teripang dengan Sistem Sasi}

Skema penangkapan teripang di Kabupaten

Kaimana dan khususnya di lokasi

penelitian,dalam menjalankan sistem sasi (Gambar 4).

\section{a. Pulau Kayumerah}

Sistem sasi di Pulau Kayumerah adalah dengan menetapkan waktu larangan pengambilan dan denda. Lokasi sasi ditutup selama dua hingga tiga tahun, setelah mencapai masa tersebut maka sasi dibuka selama dua minggu. Pada saat sasi dibuka, semua masyarakat, khususnya nelayan melakukan pengambilan teripang. Waktu 
pengambilan adalah saat air laut mencapai surut terendah ('meti'). Hasil tangkapan setiap nelayan adalah $50 \mathrm{~kg}$ kering per dua minggu atau 3,57 kg teripang kering per orang per hari. Setelah dua minggu sasi kembali diberlakukan dan bagi yang melanggar akan dikenakan denda. Denda bervariasi, ada yang harus membayar sebesar Rp. 500.000 atau membayarnya dengan piring besar sebanyak 12 buah, atau piring kecil sebanyak dua lusin.

\section{b. Kampung Kambala}

Sistem sasi di Kampung Kambala sedikit berbeda dengan sasi yang diterapkan di Pulau Kayumerah. Di kampung ini sistem sasi yang diatur adalah terkait waktu larangan pengambilan, ukuran teripang, serta denda. Lokasi sasi ditutup selama dua tahun, setelah mencapai masa tersebut maka sasi dibuka selama enam bulan. Pada saat sasi dibuka, semua masyarakat, khususnya nelayan, melakukan pengambilan teripang. Waktu pengambilan saat air laut mencapai surut terendah ("meti"). Ukuran teripang yang boleh diambil adalah yang memiliki panjang $>10 \mathrm{~cm}$. Hasil tangkapan teripang dari Kampung Kambala setiap sasi rata-rata adalah 1 ton kering teripang per 6 bulan, dengan hari melaut per bulan sebanyak 14 hari (dua meti). Menurut Kepala Desa Kambala (Chandra Tamrin, komunikasi pribadi, 7 April 2018) jumlah nelayan di desa ini adalah $132 \mathrm{KK}$. Apabila dihitung, maka hasil tangkapan teripang adalah 0,09 kg teripang kering per orang per hari. Setelah enam bulan sasi kembali diberlakukan, bagi yang melanggar akan dikenakan denda. Denda yang dikenakan adalah sebesar Rp. 2.500.000.

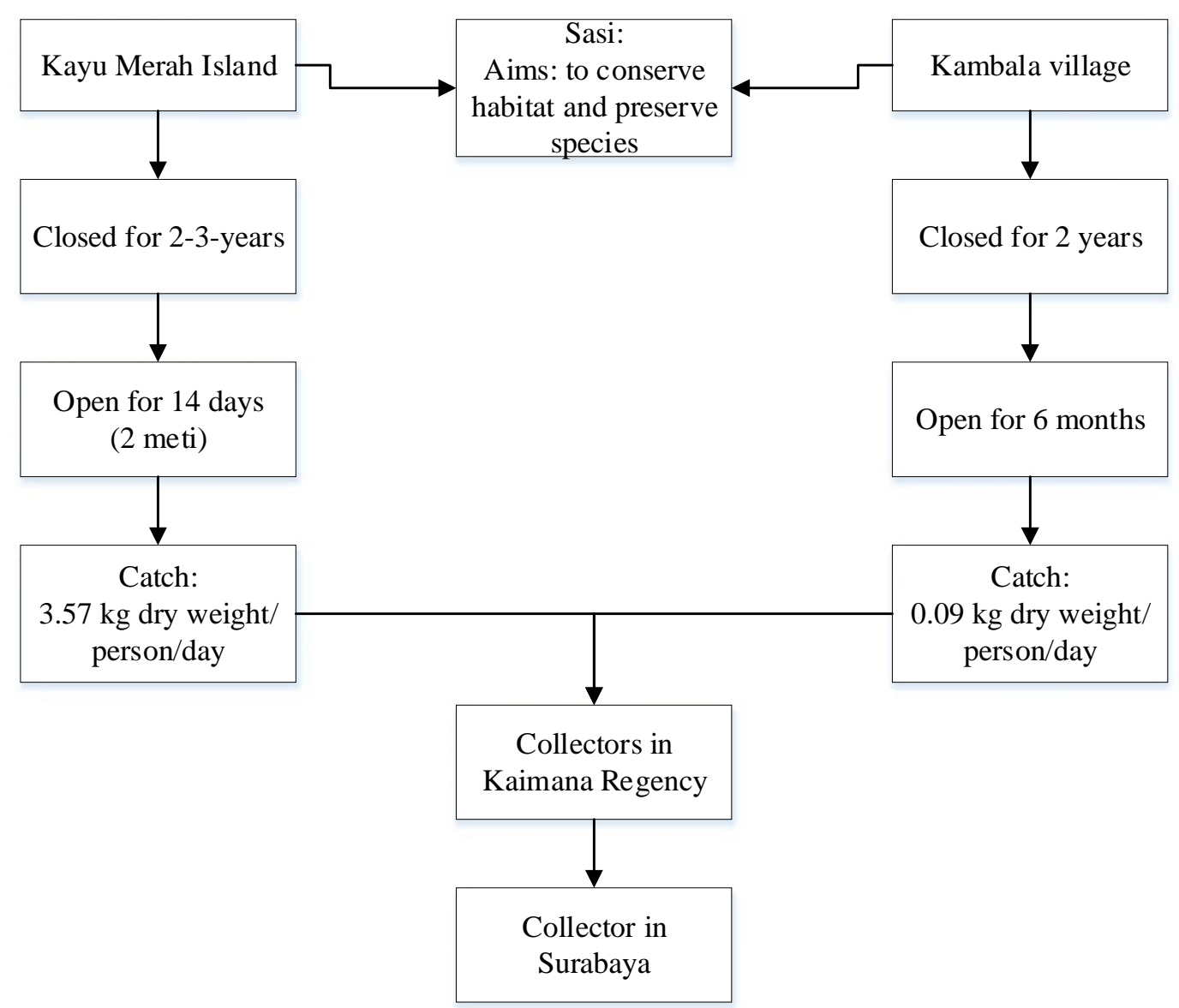

Gambar 4. Diagram sasi teripang di lokasi penelitian (sumber: data primer 2018).

Figure 4. Sasi of sea cucumber diagram at study site (source: primary data 2018).

\section{Pembahasan}

\section{Spesies Teripang}

Dibandingkan dengan lokasi lainnya, jumlah spesies teripang yang ada di Kabupaten Kaimana relatif tinggi. Tabel 4 memperlihatkan jumlah spesies teripang di beberapa lokasi di Indonesia. Dari tabel tersebut terlihat bahwa jumlah spesies teripang hasil penelitian ini lebih banyak dibandingkan dengan enam lokasi lainnya. Namun demikian, dari sisi jumlah spesies, efektivitas sasi belum cukup untuk meyimpulkan 
bahwa sasi memberikan kesempatan pada teripang untuk tumbuh dan berbiak. Sebagai contoh, jumlah teripang lebih banyak di Lampung yang berada di Indonesia bagian barat dan tidak menggunakan sistem sasi, dibandingkan di
Ambon yang menggunakan sistem sasi. Oleh karena itu, masih banyak faktor lain yang perlu dikaji, diantaranya, sebaran spesies teripang, bobot masing-masing spesies, habitat dan kualitas perairan.

Tabel 4. Jumlah spesies teripang di beberapa lokasi di Indonesia.

Table 4. Number of sea cucumber species in several locations in Indonesia.

\begin{tabular}{|c|c|c|c|c|}
\hline No & Location & Number of Species & Commercial species & Reference \\
\hline 1 & Lampung, Lampung Province & 21 & 8 & Setyastuti, 2018 \\
\hline 2 & Karimun Jawa, Central Jawa Province & 15 & 13 & Sulardiono 2016 \\
\hline 3 & Karimun Jawa, Central Jawa Province & & 7 & Setyastuti, 2017 \\
\hline 4 & $\begin{array}{l}\text { Tanjung Tiram Kecamatan Moramo } \\
\text { Utara Kabupaten Kowane Utara, } \\
\text { Southeast Sulawesi Province }\end{array}$ & 6 & & Sarmawati et al. 2016 \\
\hline 5 & $\begin{array}{l}\text { Sumbawa, West Nusa Tenggara } \\
\text { Province }\end{array}$ & 19 & 18 & Setyastuti, 2017 \\
\hline 6 & Ambon, Maluku Province & 19 & & Setyastuti, 2018 \\
\hline 7 & $\begin{array}{l}\text { Pulau Kayumerah, Kaimana, Papua } \\
\text { Barat Province }\end{array}$ & 22 & 22 & This research \\
\hline 8 & $\begin{array}{l}\text { Kampung Kambala, Kaimana, Papua } \\
\text { Barat Province }\end{array}$ & 33 & 33 & This research \\
\hline
\end{tabular}

\section{Sasi Teripang}

Penangkapan teripang di Pulau Kayumerah dan Kampung Kambala telah dilakukan sejak lama dan turun temurun. Hal ini sesuai dengan pernyataan Clark \& May (2013) (dalamPatriatna, 2016) yang menyebutkan bahwa teripang di Kaimana telah menjadi komoditas ekspor yang bernilai tinggi sejak abad ke-17 yang penangkapannya diatur melalui sasi. Hasil penelitian memperlihatkan bahwa faktor yang berpengaruh terhadap jumlah tangkapan teripang pada saat sasi dibuka, diantaranya adalah durasi sasi, dan jumlah nelayan (Gambar 4). Gambar tersebut menunjukkan bahwa jumlah tangkapan teripang yang diperoleh nelayan berhubungan dengan durasi sasi dibuka. Semakin lama durasi sasi dibuka, semakin sedikit hasil tangkapan ratarata nelayan setiap harinya. Mungkin pada saat pertama kali sasi dibuka, hasil tangkapan relatif banyak, namun menurun seiring dengan berjalannya waktu. Jumlah nelayan yang melakukan penangkapan juga mempengaruhi hasil tangkapan. Di Pulau Kayumerah, jumlah tangkapan rata-rata setiap orang per hari relatif lebih tinggi dibandingkan dengan mereka yang ada di Kampung Kambala, karena jumlah masyarakat di Kampung Kambala lebih banyak dibandingkan Pulau Kayumerah.

Sampai saat ini belum ada informasi spesifik tentang jumlah tangkapan teripang saat sasi dibuka (Tabel 5). Tapi untuk spesies tangkapan laut yang lain pernah dilaporkan, diantaranya oleh Karepesina et al. (2013) tentang sasi ikan lompa (Thryssa baelama) di Desa Haruku, Maluku tengah. Dalam publikasi mereka disebutkan bahwa saat sasi dibuka, ikan lompa yang tertangkap dijual dengan harga Rp. $5000-$ Rp. 7000 per sepuluh ekor, tidak disebutkan berapa jumlah ikan lompa yang diperoleh baik secara kuantitas maupun moneter. Selanjutnya, Elfemi (2015) mengatakan bahwa di Desa Adault, Maluku Tenggara Barat, satu keluarga dapat memperoleh hasil penjualan udang, teripang dan lola sebesar Rp 5.000.000 - Rp. 25.000.000 saat sasi dibuka selama satu bulan. 
Tabel 5. Sasi di beberapa daerah di Indonesia.

Table 5. Sasi in several locations in Indonesia.

\begin{tabular}{|c|c|c|c|c|c|c|}
\hline Location & Sasi biota's & $\begin{array}{c}\text { Closed- } \\
\text { sasi period }\end{array}$ & $\begin{array}{c}\text { Open sasi } \\
\text { period }\end{array}$ & $\begin{array}{c}\text { Yield when sasi is } \\
\text { opened }\end{array}$ & Sanction & Reference \\
\hline $\begin{array}{l}\text { Ohoider Tawun } \\
\text { village, Maluku } \\
\text { Tenggara } \\
\text { Regency }\end{array}$ & $\begin{array}{l}\text { Sea } \\
\text { cucumber, } \\
\text { Haliotis sp., } \\
\text { Trochus sp. }\end{array}$ & $1-3$ year & & & $\begin{array}{l}\text { Monetary, } \\
\text { Physics and } \\
\text { social sanction }\end{array}$ & $\begin{array}{l}\text { Kusapy et } \\
\text { al., } 2005\end{array}$ \\
\hline $\begin{array}{l}\text { Haruku village, } \\
\text { Maluku Tengah } \\
\text { Regency }\end{array}$ & $\begin{array}{l}\text { Fish (Thryssa } \\
\text { baelama) }\end{array}$ & 5-7 month & $1-2$ day & $\begin{array}{l}\text { Fish price was } \\
\text { IDR 5,000 - IDR } \\
7,000 \text { per } 10 \text { fish }\end{array}$ & & $\begin{array}{l}\text { Karepesina } \\
\text { et al., } 2013\end{array}$ \\
\hline $\begin{array}{l}\text { Adaut village, } \\
\text { Maluku } \\
\text { Tenggara Barat } \\
\text { Regency }\end{array}$ & $\begin{array}{l}\text { Lobster, Sea } \\
\text { cucumber, } \\
\text { Trochus } \text { sp. }\end{array}$ & 3 year & $\begin{array}{l}1 \text { month } \\
\text { (April or } \\
\text { May }\end{array}$ & $\begin{array}{l}\text { IDR } \\
10,000,000 / \text { family, } \\
\text { ranges between } \\
\text { IDR 5,000,000 - } \\
\text { IDR } \\
25,000,000 / \text { family }\end{array}$ & & $\begin{array}{l}\text { Elfemi, } \\
2015\end{array}$ \\
\hline $\begin{array}{l}\text { Distrik Misool } \\
\text { Barat, } \\
\text { Kabupaten } \\
\text { Rajaampat }\end{array}$ & $\begin{array}{l}\text { Lobster, Sea } \\
\text { cucumber, } \\
\text { Trochus sp. }\end{array}$ & $\begin{array}{c}6 \text { month } \\
\text { (monthly } \\
\text { sasi), } \\
1-2 \text { year } \\
\text { (yearly } \\
\text { sasi) }\end{array}$ & 3-7 day & & & $\begin{array}{l}\text { Lestari \& } \\
\text { Satria, } 2015\end{array}$ \\
\hline $\begin{array}{l}\text { Haruku, village } \\
\text { Maluku Tengah } \\
\text { Regency }\end{array}$ & $\begin{array}{l}\text { Fish (Thryssa } \\
\text { baelama) }\end{array}$ & $\begin{array}{l}\text { 4-8 month } \\
-1 \text { year }\end{array}$ & & & & $\begin{array}{l}\text { Asrul et al } \\
2017\end{array}$ \\
\hline $\begin{array}{l}\text { Kayumerah } \\
\text { Island, Kaimana } \\
\text { Regency }\end{array}$ & Sea cucumber & $2-3$ year & 14 day & $\begin{array}{l}3.57 \\
\mathrm{~kg} / \text { person/day }\end{array}$ & $\begin{array}{l}\text { IDR } 500.000 \\
\text { or } 12 \text { pieces of } \\
\text { big dishes or } \\
14 \text { pieces of } \\
\text { dishes }\end{array}$ & $\begin{array}{l}\text { This } \\
\text { research, } \\
2018\end{array}$ \\
\hline $\begin{array}{l}\text { Kambala village, } \\
\text { Kaimana } \\
\text { Regency }\end{array}$ & Sea cucumber & 2 year & 6 month & $\begin{array}{l}0.09 \\
\mathrm{~kg} / \text { person/day }\end{array}$ & IDR $2,500,000$ & $\begin{array}{l}\text { This } \\
\text { research, } \\
2018\end{array}$ \\
\hline
\end{tabular}

Hasil sasi teripang mungkin memberikan kontribusi yang signifikan terhadap produksi teripang di Kabupaten Kaimana. Dari Surat Keterangan Asal (SKA) yang diperoleh dari Dinas Perikanan Kabupaten Kaimana, produksi teripang berfluktuasi (Gambar 5.). Akan tetapi gambar ini menunjukkan bahwa produksi teripang pada tahun 2016 relatif tinggi dibandingkan dengan tahun sebelum dan sesudahnya. Hasil wawancara penulis dengan salah seorang petuanan di Pulau Kayumerah menyatakan bahwa sasi di Pulau Kayumerah telah dibuka pada tahun 2016 dan akan dibuka kembali pada bulan Oktober 2018 (Rudy Boimasa, komunikasi pribadi, 6 April
2018). Sementara itu, informasi dari pengepul diketahui bahwa saat tutup sasi mereka membeli teripang dari Fak-fak, Sorong, Saumlaki dan Seram. Artinya, produksi teripang yang tercatat di Dinas Perikanan Kabupaten Kaimana bukan berasal dari hasil sasi, melainkan berasal dari daerah lain.

Informasi tersebut diduga sebagai salah satu bukti yang menerangkan mengapa pada tahun 2016 produksi teripang di Kabupaten Kaimana relatif tinggi, sedangkan pada tahun 2015 dan 2017, produksi teripang di Kabupaten Kaimana, lebih rendah, berkisar antara 5-6 ton. 
Sjafrie \& Setyastuti

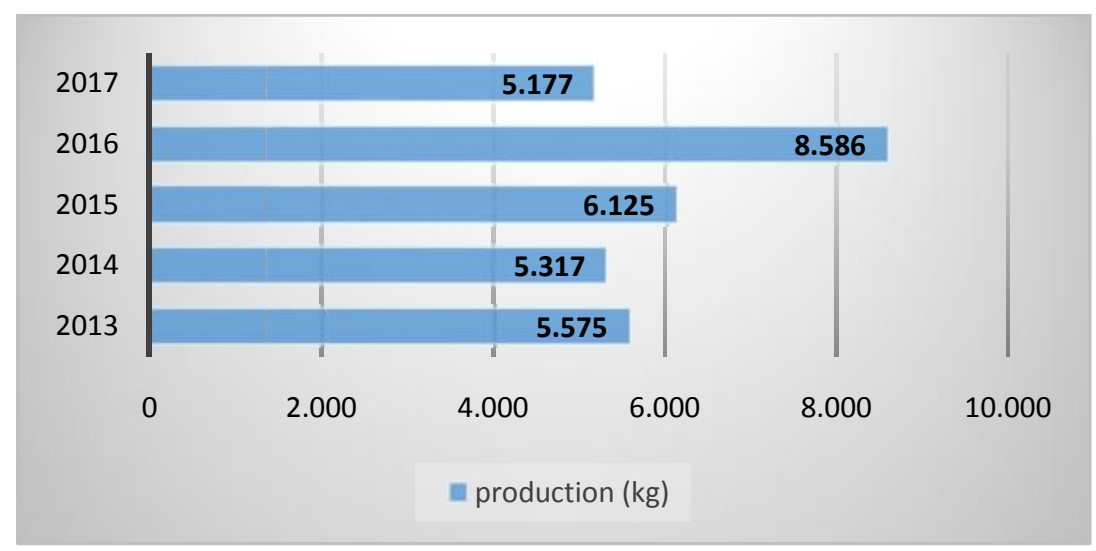

Gambar 5. Produksi teripang tahun 2013-2017 di Kabupaten Kaimana.

Figure 5. Sea cucumber production in 2013-2017 in Kaimana Regency.

Studi literatur diketahui bahwa perubahan sistem sasi memberikan pengaruh terhadap keberlanjutan sasi yang berujung pada keberlanjutan pemanfaatan sumber daya alam termasuk teripang. Keberlanjutan sasi dipengaruhi antara lain oleh homogenitas masyarakat; perayaan sasi; keterisolasian daerah seperti akses pasar, ketersediaan pekerjaan, pendidikan serta legitimasi, apakah seorang ketua berasal dari keturunan adat dan memiliki kemampuan memahami sumber daya (McLeod et al., 2009). Selanjutnya, Patriatna et al. (2016) menyatakan bahwa telah terjadi perubahan kelembagaan sasi di Kampung Adijaya, Kecamatan Buruway, Kabupaten Kaimana akibat faktor ekonomi yang menimbulkan pergeseran orientasi dari konservasi menjadi komersialisasi, misalnya perubahan teknik penangkapan dan sistem lelang. Selain itu timbulnya distorsi orientasi dari kepentingan masyarakat menjadi kepentingan individu. Sasi laut dapat terhenti karena terjadi kerusakan ekosistem, masalah pasar, masalah sosial serta masalah kelembagaan adat (Ananingsih, 2018).

Apabila dikaitkan dengan keadaan yang ada di lokasi penelitian, maka hal-hal yang terekam dan dapat mempengaruhi keberlangsungan sasi adalah perubahan cara penangkapan, diterapkannya sistem lelang pada arealsasi dan pengambilan teripang yang berbayar. Di Kampung Kambala pengambilan teripang selain dengan berjalan kaki juga sudah dilakukan dengan menyelam menggunakan kompresor. Artinya nelayan teripang dapat melakukan pengambilan teripang di perairan yang lebih dalam yang mengakibatkan terkurasnya sumber daya teripang di perairan tersebut. Tarif yang dikenakan untuk nelayan yang mengikuti panen saat sasi diuka adalah sebesar Rp. 500.000, sedangkan yang menggunakan kompresor sebesar Rp. 1.500.00, tarif tersebut ditetapkan dan diberikan pada kepala kampung atau petuanan. Di kampung ini juga telah diterapkan sistem lelang pada areal sasi, yang artinya telah terjadi komersialisasi. Sebaliknya di Pulau Kayumerah, pengambilan teripang dilakukan dengan cara berjalan kaki dan menyelam menggunakan kompresor, namun tidak diterapkan sistem lelang. Sasi di lokasi penelitian tampaknya telah mengalami pergeseran yang berakibat pada berkurangnya ketersediaan sumber daya teripang yang ada. Hal ini telah terungkap saat wawancara dilakukan (lihat Tabel 2). Ke depan, perlu kajian lebih mendalam mengenai bio-reproduksi teripang, jumlah dan ukuran maksimum teripang yang boleh diambil dan kondisi habitat teripang.

\section{Kesimpulan}

Perairan Kabupaten Kaimana masih menyimpan berbagai spesies teripang ekonomis penting. Durasi sasi dan masyarakat yang terlibat di dalam sasi menjadi faktor yang mempengaruhi hasil tangkapan saat sasi dibuka. Pemanfaatan teripang dengan sistem sasi merupakan salah satu alternatif untuk menjaga ketersediaan sumber daya teripang. Namun, praktek sasi di lokasi penelitian tampaknya telah mengalami pergeseran dengan diterapkannya sistem lelang, perubahan alat tangkap serta pengambilan teripang yang berbayar.

\section{Persantunan}

Penelitian ini masuk dalam pendanaan skema Riset Prioritas COREMAP-CTI dengan subtema Biota Laut Terancam Punah, SK Puslit Oseanografi LIPI nomor B-175/IPK.2/KP.06 /I/2018. Penulis mengucapkan terima kasih kepada Sandi Permadi, SSi dan Nurdjamin dari Pusat Penelitian Oseanografi LIPI serta Junaidi 
dari Badan Pengelola Sumber Daya Pesisir dan Laut (BPSPL) Sorong Kementrian Kelautan dan Perikanan yang telah membantu pengambilan data di lapangan.

\section{Kontribusi}

Nurul Dhewani Mirah Sjafrie berperan sebagai kontributor utama dan Ana Setyastuti sebagai kontributor anggota dalam artikel ini.

\section{Daftar Pustaka}

Aditya, A. (2017). Sasi Nggama Budaya Konservasi Laut Unik dari Papua. https://lanangindonesia.com/read/sasinggama-budaya-konservasi-laut-unik-daripapua.

Ananingsih, S.W. (2018). The development of sasi laut in the preservation of sea in Kei Community. E3S Web of Conferences 31, 09029 (2018).

https://doi.org/10.1051/e3sconf/201831090 29

Asrul, Rindarjono, M.G.,\& Sarwono. (2017). Eksistensi Sasi dalam pengelolaan lingkungan hidup dan peranserta masyarakat di Negeri Haruku Kabupaten Maluku Tengah Propinsi Maluku Tahun 2013. Jurnal GeoEco,3(1), 68-81.

Badan Pusat Statistik Kabupaten Kaimana. (2016a). Distrik Buruway dalam Angka 2016. Kaimana, Indonesia: Author.

Badan Pusat Statistik Kabupaten Kaimana. (2016b). Distrik Teluk Etna dalam Angka 2016. Kaimana, Indonesia: Author.

Badan Pusat Statistik Kabupaten Kaimana. (2016c). Kabupaten Kaimana Dalam Angka.Kaimana, Indonesia: Author.

Badan Pusat Statistik Kabupaten Kaimana. (2017). Produk Regional Domestik Bruto Kabupaten Kaimana Tahun 2013-2017. Kaimana, Indonesia: Author.

Betaubun, A.D.S., Laiyanan, S.E.B., Renyaan, D., \& Penturyet, F. (2019). Persepsi penerapan Sasi Laut di Wilayah Perairan Kepulauan Kei: Upaya Mendukung Keberlanjutan Sumber Daya Laut. Jurnal Agribisnis Perikanan, 12(1), 136-144.

DOI: 10.29239/j.agrikan.12.1.136-144

Choo, P.S. (2008). Population status, fisheries and trade of sea cucumbers in Asia. In V. ToralGranda, A. Lovatelli and M. Vasconcellos (eds). Sea cucumbers. A global review of fisheries and trade. FAO Fisheries and
Aquaculture Technical Paper. No. 516. Rome, FAO. pp. 81-118.

Direktorat Konservasi Kawasan dan Jenis Ikan Direktorat Jenderal Kelautan, Pesisir dan Pulau-Pulau Kecil Kementerian Kelautan dan Perikanan. (2015). Profil Kawasan Konservasi Papua Barat.Jakarta, Indonesia: Author.

Dinas Perikanan Kabupaten Kaimana. (2017). Data teripang dalam bentuk worksheet.

Elfemi, N. (2015). Sasi, Kearifan Lokal Dalam Pengelolaan Sumber Daya Laut (Kasus; Masyarakat suku Tanimbar di Desa Adaut, Kecamatan Selaru, Kabupaten Maluku Tenggara Barat). Jurnal Pelangi,6(1), 2330.

http://dx.doi.org/10.22202/jp.2013.v6i1.281

Hartati, S.T., Wahyuni, I.S., Suprapto, \& Reswati, E. (2002). Perikanan teripang di perairan Kepulauan Seribu. J. Lit. Perikan. Ind. Ed. Sumber Daya dan Penangkapan,8(4), 5-64.

https://petatematikindo.files.wordpress.com/2013/ 02/administrasi-kaimana.jpg. Diakses tanggal 14 Juli 2020

Judge, Z.,\& Nurizka, M. (2008). Peranan Hukum Adat Sasi Laut dalam melindungi kelestarian lingkungan di Desa Eti Kecamatan Seram Barat Kabupaten Seram Bagian Barat. Lex Jurnalica,6(1), 30-61.

Karepesina, S.S., Susilo, E.,\& Indrayani, E. (2013). Eksistensi hukum adat dalam melindungi pelestarian Sasi Ikan Lompa Di Desa Haruku Kabupaten Maluku Tengah. Jurnal ECSOFiM, 1(1), 25-40.

Konsul Perdagangan, Konsulat Jendral Republik.ndonesia Hongkong SAR. (2016). Teripang (HS 0308.19) di Pasar Hongkong SAR. Laporan Market Brief Edisi April 2016. Republik Rakyat Cina: Author.

Kusapy, D.L., Lay, C.,\& Kaho, Y.R. (2005). Manajemen konflik dalam pemanfaatan sumberdaya alam dan pelestarian lingkungan hidup lewat pelaksanaan hukum adat Sasi. Manusia dan Lingkungan,12(3), 130-139.

Kuwati, Martosupono, M. \& Mangimbulude, J.C. (2014a). Konservasi Berbasis Kearifan Lokal (Studi Kasus: Sasi di Kabupaten Rajaampat. Dalam Prosiding Seminar Nasional Raja Ampat, Waisai 12-13 Agustus 2014: A9. 7 hal.

Kuwati, Martosupono, M. \& Mangimbuludeet, J.C. (2014b). Peran Sasi Dalam Melindungi Sumberdaya Teripang Di Kampung Folley, Kabupaten Raja Ampat. Dalam Prosiding 
Seminar Nasional Raja Ampat, Waisai 1213 Agustus 2014: A19. 5 hal.

Lestari, E., \& Satria, A. (2015). Peranan Sistem Sasi Dalam Menunjang Pengelolaan Berkelanjutan pada Kawasan Konservasi Perairan Daerah Raja Ampat. Buletin Ilmiah Marina Sosek Kelautan dan Perikanan, 1(2), 67-76.

McLeod, E., Szuster, B.,\& Salm, R. (2009). Sasi and Marine Conservation in Raja Ampat, Indonesia. Coastal Management, 37,656676.

Pangestuti, R.,\& Arifin, Z. (2018). Medicinal and health benefit effects of functional sea cucumbers. Journal of Traditional and Complementary Medicine, 8, 341-351.

Pangestuti, R., Murniasih, T., Putra, M.Y., Rasyid, A., Wibowo, J.T., Ardiansyah, A.,\& Untari, F. (2016). Free radical scavenging activity of selected Sea Cucumber Species from Mataram-Lombok, Indonesia. Jurnal Teknologi (Sciences \& Engineering),78(4-2), 179-185.

Patriatna, R., Adiwibowo, S., Kinseng, R.A.,\& Satria, A. (2016). Perubahan kelembagaan dalam pengelolaan sumber daya laut tradisional (Kasus Kelembagaan Sasi di Kaimana). Sodality: Jurnal Sosiologi Pedesaan, 257-264.

Purcell, S.W., Williamson, D.H.,\& Ngaluafe, P. (2018). Chinese market prices of beche-demer: Implications for fisheries and aquaculture. Marine Policy, 91, 58-65

Pusat Penelitian Oseanografi LIPI. (2018). Petunjuk Lapangan Teripang.Jakarta, Indonesia: Author.

Putri, F.R.D., Satria, A.,\& Saharuddin. (2020). Sasi Laut Folley dan dinamika pengelolaan berbasis masyarakat.Journal of Natural Resources and Environmental Management, 10(1), 111-123. http://dx.doi.org/10.29244/jpsl.10.1. 111123

Sarmawati, Ramli, M.,\& Ira. (2016). Distribusi dan kepadatan Teripang (Holothuroidea) di Perairan Tanjung Tiram Kecamatan
Moramo Utara Kabupaten Konawe Selatan. Jurnal Manajemen Sumber Daya Perairan, 1(2), 183-194.

Setyastuti, A. (2017). Teripang Indonesia: Eksplorasi, Pengelolaan dan Keterkaitannya dengan Oseanografidi Perairan Indonesia. Laporan Kegiatan Tematik Tahun Pertama. Pusat Penelitian Oseanografi LIPI. 29 hal.

Setyastuti, A., Purbiantoro, W.,\& Hadiyanto. (2018). Spatial distribution of echinoderms in littoral area of Ambon Island, Eastern Indonesia. Biodiversitas, 19(5). 1919-1925.

Setyastuti, A., Wirawati, I.,\& Iswari, M.Y. (2018). Identification and distribution of sea cucumber exploited in Lampung, Indonesia. Biodiversitas, 19(2), 726-732.

Soulhany, R. (2016). Sasi adat kajian terhadap pelaksanaan sasi adat dan implikasinya. KENOSIS, 2(2), 192-205.

Sulardiono, B. (2016). Potensi pemanfaatan Teripang (Holothurians) di Perairan Karimunjawa, Kabupaten Jepara, Provinsi Jawa. Buletin Oseanografi Marina,5(1), 6472.

Suntoko, Pudentia,\& Ruhaliah. (2016). Sasi role of tradition in the management and conservation of natural resources as a source of human life. International Journal of Education and Research, 4(6), 333-340.

Ummanah, 2013. Sasi Laut Komunitas Nelayan Di Maluku Tenggara, Provinsi Maluku. Jurnal Ilmiah Pariwisata, 18(3), 174-183.

Warawarin, C.Y., Cangara, H.,\& Muhadar. (2017). Makna komunikasi simbolik hukum adat sasi dalam pelestarian alam laut di Kabupaten Maluku Tenggara. Jurnal Komunikasi KAREBA,6(1), 1-19.

Wiadnyana, N.N., Puspasari, R. \& Mahulette, R.T. (2018). Status sumber daya dan perikanan teripang di Indonesia: pemanfaatan dan perdagangan. Jurnal Kebijakan Perikanan Indonesia,1(1), 4560. 